\title{
Protective Effects of Sodium Butyrate on Rotavirus Inducing Endoplasmic Reticulum Stress-Mediated Apoptosis Via PERK-elF2a Signaling Pathway in IPEC-J2 Cells
}

Ye Zhao ( $\nabla$ zhye3@foxmail.com )

Sichuan Agricultural University

Ningming Hu

Sichuan Agricultural University

Qin Jiang

Sichuan Agricultural University

Li Zhu

Sichuan Agricultural University

Ming Zhang

Sichuan Agricultural University

Jun Jiang

Sichuan Agricultural University

Manyi Xiong

Sichuan Agricultural University

Mingxian Yang

Sichuan Agricultural University

Jiandong Yang

Sichuan Agricultural University

Linyuan Shen

Sichuan Agricultural University

Shunhua Zhang

Sichuan Agricultural University

Lili Niu

Sichuan Agricultural University

Lei Chen

Sichuan Agricultural University

Daiwen Chen

Sichuan Agricultural University 
Research

Keywords: Rotavirus, PERK-elF2a, Apoptosis, IPEC-J2, Sodium butyrate

Posted Date: December 21st, 2020

DOl: https://doi.org/10.21203/rs.3.rs-130928/v1

License: (c) (i) This work is licensed under a Creative Commons Attribution 4.0 International License. Read Full License 


\section{Abstract}

Background: Rotavirus (RV) is an important pathogens that causes severe gastroenteritis in infants and young animals. Endoplasmic reticulum (ER) stress and subsequent apoptosis played pivotal role in virus infection. However, the protective mechanisms of intestinal damage caused by RV are poorly defined, especially the molecular pathways related to enterocytes apoptosis. Thus, the aim of this study was to investigate the protective effect and mechanism of sodium butyrate (SB) on RV-induced apoptosis of IPEC-J2 cells.

Results: The RV infection led to significant cell apoptosis, increased the expression levels of ER stress (ERS) markers, phosphorylated protein kinase-like ER kinase (PERK), phosphorylated eukaryotic initiation factor 2 alpha (elF2a), caspase9, and caspase3. Blocking PERK pathway using specific inhibitor GSK subsequently reversed RV-induced cell apoptosis. The SB treatment significantly inhibited RV-induced ERS by decreasing the expression of glucose regulated protein 78 (GRP78), PERK, and elF2a. In addition, SB treatment restrained the ERS-mediated apoptotic pathway, as indicated by downregulation of C/EBP homologous protein (CHOP), as well as decreased cleaved caspase 9 and 3. Furthermore, siRNA-induced GPR109a knockdown significantly suppressed the protective effect of SB on RV-induced cell apoptosis.

Conclusion: Taken together, these findings revealed that SB exerts protective effects against RV-induced cell apoptosis through inhibiting ERS mediated apoptosis via PERK-elF2a signaling pathway in a GPR109a-dependent manner, which provide new ideas for the prevention and control of RV.

\section{Introduction}

Rotavirus (RV) is the major cause of viral gastroenteritis in infants, young children, and young animals around the globe, with 12000 to 15000 annual deaths among children under 5 years attributed to RV infections [1-5]. The RV are transmitted via the faecal-oral route. The faeces from an infected host contains more than 10 trillion pfu/gr of viruses per gram, but less than 100 of them can transmit infection and make someone else sick [6]. The RV primary infects mature enterocytes and results in blunting, atrophy and fusion of villi, denudation of tip of villi and cryptal cells hyperplasia, thereby disrupting their physiological and absorptive function, which lead to diarrhoea [7, 8]. Epidemiological researches have confirmed that RV in environment could contribute to the development of infectious gastrointestinal illness, which raising serious concerns about impacts on public health $[9,10]$. The detrimental effects of RV on public health have prompted substantial concern about how to efficiently protect the human or animal against RV infection.

Human or animal exposed to RV in natural environment have been reported to exert chronic sublethal effects, increasing concern about environmental risk [11-13]. The RV infection causes intestinal barrier dysfunction and disrupts intestinal homeostasis, which could induce the apoptosis of epithelial cells [7, 14]. Endoplasmic reticulum (ER) is a vital organelle that performs a variety of intracellular processes, including synthesis, folding, and post-translational modifications of proteins, and apoptosis, whose 
homeostasis is crucial for epithelial cells $[15,16]$. Emerging reports have confirmed that virus infection could lead to impaired ER homeostasis in host cells and eventually lead to ER stress (ERS) [15, 17]. The protein kinase RNA-like ER kinase (PERK) is one of the major ER transmembrane protein that is phosphorylated upon ERS. Subsequently, activation of PERK lead to the phosphorylation of a-subunit of eukaryotic initiation factor 2 alpha (elF2a) [18]. Phosphorylated elF2a promotes the induction of activating transcription factor 4 (ATF4), which induced the expression of pro-apoptotic C/EBP homologous protein (CHOP) [19]. The CHOP promoted apoptosis by increasing expression of the proapoptotic factor Bax and suppressing the expression of the anti-apoptotic Bcl-2 [20, 21]. So far, numerous viruses have been demonstrated to induce cell apoptosis via PERK-elF2a-CHOP signaling pathway in infected cells [22, 23]. Nevertheless, whether RV could cause ERS-mediated cell apoptosis remains to be investigated.

Sodium butyrate (SB), a natural short chain 4-carbon fatty salt, has been endogenously produced during the microbial fermentation of dietary fiber in the colon [24]. Published studies have reported that SB has a wide range of pharmacological properties, including anti-inflammation, anti-oxidation, antitumor activities, and metabolism regulation [25-29]. Newer study showed SB prevented tert-butyl hydroperoxide-induced apoptosis in human nucleus pulposus cells [30]. The SB could lessen ER-stress induced apoptosis in type 2 diabetic rats [31]. Desipite, those results suggested that SB might play a critical role in reducing cell apoptosis. It is unknown whether SB prevents RV-induced cell apoptosis. Based on the established RV infected intestinal epithelial cell model [32], this study is the first report to uncover the ER-mediated apoptosis and potential molecular mechanism caused by RV infection. Then protective effects of SB against RV-induced cell apoptosis were investigated. These findings provide new ideas for prevention and control of RV.

\section{Materials And Methods}

\subsection{Cell culture and viral infection}

The IPEC-J2 cell line (obtained from professor Per Torp Sangild, University of Copenhagen, Denmark) from the same passage were planted in DMEM/F12 medium supplemented with $10 \%$ fetal bovine serum, antibiotics (1\% penicillin-streptomycin), $5 \mathrm{mg} / \mathrm{ml} \mathrm{hEGF}$, and $10 \mathrm{nM} \mathrm{HEPES}$, under an incubator of $5 \% \mathrm{CO}_{2}$ at $37^{\circ} \mathrm{C}$. The RV strain was purchased from China Institute of Veterinary Drug Control. Confluent $(80 \%)$ IPEC-J2 cells were infected with RV at multiplicity of infection (MOI) of 10 at $37^{\circ} \mathrm{C}$ for $1 \mathrm{~h}$. After that, the inoculum was carefully removed, and the cells were washed twice with cold PBS and cultured in fresh growth medium.

\subsection{PERK inhibitor treatments}

The cells were pre-treated with the PERK inhibitor GSK $(1.0 \mu \mathrm{M}$ and $10 \mu \mathrm{M})$ for $24 \mathrm{~h}$, followed by challenge with RV (10 MOI) for $1 \mathrm{~h}$, and then cultured with DMEM/F12 for a further $24 \mathrm{~h}$.

\subsection{SB treatments}


The SB (Sigma Aldrich, St. Louis, MO, USA) was dissolved in DMEM/F12 medium. Experimental procedures were based on the methods in our laboratory [32]. Briefly, cells were cultured with different concentrations of $\mathrm{SB}(0,1,4,8$, and $16 \mathrm{mM})$ at $37^{\circ} \mathrm{C}$ with $5 \% \mathrm{CO}_{2}$ for $24 \mathrm{~h}$, followed removing medium and washing the cells with PBS three times, then challenged with RV at MOI of 10 for $1 \mathrm{~h}$. Next, removal of the inoculums and washing twice with PBS, the cells were incubated with basal medium (serum free) containing SB $(0,1,4,8$, and $16 \mathrm{mM})$ for a further $24 \mathrm{~h}$.

\subsection{RNA Interference}

GPR109a-specific siRNA1 (CGATGTTAATCAAGAAGCA), siRNA2 (GTAGCTTCAGCAT CTGCAA), and negative control siRNA (siCtrl) (RiboBio, Guangzhou, china) were used to knockdown GPR109a. The siGPR-109a and siCtrl were transfected into IPEC-J2 using lipofectamine 3000 (Invitrogen, USA) following the manufacturer's proceduress.

\subsection{Determination of cell viability and apoptosis}

The IPEC-J2 cells under different conditions seeded in sterile 96 -well plates with cell density of $4 \times 10^{4}$ $\mathrm{ml}^{-1}$ with $100 \mu \mathrm{L}$ medium. The Cell Counting Kit-8 (CCK-8) kit (Dojindo, Kumamoto, Japan) was adopted to measure the cell viability. Cell apoptosis was detected by Fluorescein isothiocynate (FITC)-, Alexa Fluor ${ }^{\circledR} 647$ - conjugated Annexin $V$ with propidium iodide (PI) staining assay (Biolegend) according to the manufacturer's protocols. Briefly, IPEC-J2 cells from the control and RV (GSK or SB or siRNA1) -treated groups were harvested and rinsed twice with cold PBS. Then, cells were resuspended in $100 \mu \mathrm{L} 1 \times$ binding buffer and incubated with Alexa Fluor®647- conjugated Annexin V (2 $\mu \mathrm{L}$ per $10^{6}$ cells) for 20 min on ice. Subsequently, $400 \mu \mathrm{L} 1 \times$ binding buffer and $1 \mu \mathrm{L} \mathrm{PI}\left(1 \mathrm{mg} \mathrm{ml}^{-1}\right)$ was added successively and immediately analyzed by flow cytometry.

\subsection{Real-time quantitative PCR}

Total RNA was isolated from IPEC-J2 cells using RNAiso reagent (Invitrogen, Carlsbad, CA, USA) according to the manufacturer's instructions, followed by the synthesis of cDNA by the prime script ${ }^{\mathrm{TM}} \mathrm{RT}$ reagent kit with gDNA eraser (Takara, Dalian, China). The RNA purity and integrity were assessed by spectrophotometric (A260 and $280 \mathrm{~nm}$ ratio) analysis and agarose gel (1\%) electrophoresis, respectively. Real-time quantitative PCR was carried out with a SYBR Premix EX Taq kit (TaKaRa, Dalian, China) and the CFX96 Real-Time PCR Detection System (Bio-Rad, Hercules, CA, USA). Relative gene expression was calculated with the $2^{-\triangle \Delta C T}$ method, normalizing the results to the value for the $\beta$-actin gene. Primer sequences used in this experiments are shown in Table 1.

\subsection{Western blotting}

Protein was isolated from cells using cold lysis buffer containing a proteinase and phosphatase inhibitor cocktail (Beyotime, Shanghai, China). The protein concentrations in the supernatants were measured using a BCA protein quantification kit (Beyotime, Shanghai, China). Samples containing equal amounts of protein $(20 \mu \mathrm{g})$ were separated by $10 \%$ SDS-polyacrylamide gel electrophoresis and then transferred to a polyvinyldifluoride membrane (Bio-Rad Co. USA). The membranes were blocked and then incubated 
overnight at $4{ }^{\circ} \mathrm{C}$ with primary antibody (PERK, Santa Cruz Biotechnology, catalogue no.sc-377400; phospho-PERK (p-PERK), Abcam, catalogue no. ab192591; elF2a, Cell Signaling, catalogue no.5324; phospho-elF2a (p-elF2a), Abcam, catalogue no. Ab32157; caspase9, Cell Signaling, catalogue no.9504; caspase3, Cell Signaling, catalogue no. D3R6Y; $\beta$-actin, Cell Signaling, catalogue no. D6A8), washed four times using TBST ( 5 min each time). Then, the membrane was incubated with the corresponding HRPconjugated secondary antibody at $25^{\circ} \mathrm{C}$ for $1 \mathrm{~h}$, washed four times with TBST for $20 \mathrm{~min}$, and visualized using ECL chemiluminescence kit (Beyotime, Shanghai, China). Finally, the Gel-Pro Analyzer was used to analyze protein densitometry. The relative expression levels of all protein were normalized to $\beta$-actin.

\subsection{Statistical analysis}

All results are expressed as means \pm SD. Data were analyzed using the statistical software SPSS 19.0 (SPSS Inc., Chicago, IL). All results were unpaired two-tailed Student's T test and/or one-way analysis of variance (ANOVA). $P<0.05$ and $P<0.01$ were considered to be statistically significant $\left(^{\star}\right)$ and markedly significant $\left.{ }^{\star *}\right)$ respectively.

\section{Results}

\subsection{RV induces ERS mediated apoptosis in IPEC-J2 cells}

Initially, to define whether RV induce ERS mediated cell apoptosis, different assays were conducted in uninfected- and RV-infected IPEC-J2 cells at $24 \mathrm{~h}$ post-infection. As shown in the Fig. 1A and 1B, RV infection inhibited cell proliferation in a MOI-dependent mode. By using flow cytometry analysis, the percentage of apoptosis IPEC-J2 cells increased to $34.24 \%$ from a baseline of $9.08 \%$ after RV infection. In response to RV infection, an increase in the mRNA level of ERS marker GRP78 was observed (Fig. 1C). As shown in Fig. 1C and 1D, the mRNA levels of PERK, CHOP, caspase9, and caspase3 were significantly increased in $24 \mathrm{~h}$ post infected cells. Inhibition of PERK by GSK potently promoted the proliferation (Fig. 2A) and down-regulated caspase9 and caspase3 mRNA expression (Fig. 2C) of RV-infected IPEC-J2 cells. The apoptosis rate in RV infected cells pretreated with GSK $(10 \mu \mathrm{M})$ was significantly decreased compared to that in RV infected cells (Fig. 2B). Western blot analysis showed that p-PERK/t-PERK, $p$ elF2a/t-elF2a, cle-caspase9, and cle-caspase3 were significantly increased in $24 \mathrm{~h}$ post infected cells, while their expression levels were significantly decreased with PERK inhibitor treatment (Fig. 3A and 3B). These results collectively suggest that RV activates ERS and PERK/elF2asignaling pathway, which maybe an important reason of RV-induced cell apoptosis.

\subsection{SB ameliorates RV induced ERS mediated apoptosis in IPEC-J2 cells}

To determine whether SB could exert a protective effect against RV induced cell apoptosis. This study first examined the effect of SB on the IPEC-J2 cells viability at various concentrations. The SB had no cytotoxic effects up to the concentration of $8 \mathrm{mM}$ (Fig. 4A) and tended (2 and $4 \mathrm{mM}$ ) to alleviate RV induced the decrease of the cell viability (Fig. 4B). Further the number of apoptotic cells after SB 
treatment was measured by using flow cytometry analysis. As expectedly, pretreatment of SB significantly decreased the apoptosis in RV-infected IPEC-J2 cells (Fig. 4C). As shown in Fig. 5A, B, C, D, E, $\mathrm{F}$, and $\mathrm{G}$, pretreated with SB (4 and $8 \mathrm{mM}$ ) cells showed a significant decrease in GRP78, PERK, CHOP, caspase9, and caspase 3 mRNA expressions in RV infected IPEC-J2 cells. Together, these results suggested SB might ameliorates RV induced cell apoptosis via PERK-elF2a signaling pathway in IPEC-J2 cells.

\subsection{SB ameliorates RV induced cell apoptosis via GPR109a in IPEC-J2 cells}

To detect whether SB ameliorates RV induced cell apoptosis via GPR109a, this study first examined the effect of SB on GPR109a in RV infected IPEC-J2 cell. The result indicated GPR109a mRNA expression was up-regulated significantly after the addition of SB (Fig. 6). Then, two small interfering RNAs against GPR109a (GPR109a siRNA1 and GPR109a siRNA2) were transfected into IPEC-J2 cell. Compared with siRNA control, the expression of GPR109a were significantly down-regulated by GPR109a siRNAs (Fig. 7A), and transfection efficiency of siRNA1 was more significant than siRNA2 (data not shown). After SB treatment, the mRNA expression of GPR109a was significantly decreased by GPR109a siRNA1 in RV infected IPEC-J2 (Fig. 7B). Therefore, GPR109a siRNA1 was chose in the following experiments. Flow cytometry assays indicated GPR109a siRNA1 conspicuously increased apoptosis rate in RV infected IPEC-J2 cell (Fig. 7C). Besides, GPR109a siRNA1 remarkably suppressed the decrease of SB on GRP78, PERK, elF2a, ATF4, CHOP, Bcl2, caspase9, and caspase3 in RV infected IPEC-J2 (Fig. 7D). Western blot results showed that SB strongly decreased protein levels of p-PERK, p-elF2a, cle-caspase9, and clecaspase3, but GPR109a siRNA1 attenuated this decrease in RV infected IPEC-J2 (Fig. 7E and 7F). In a word, these data revealed SB ameliorated RV induced cell apoptosis via PERK/elF2asignaling pathway in a GPR109a-dependent manner.

\section{Discussion}

As an important pathogenic factor, RV recently presents potential hazards to public health [33, 34]. Enterocytes are the first block of defence against the entry of pathogens and bacteria in the gut lumen. The IPEC-J2 cell line, isolated from the mid-jejunum epithelium of a neonatal un-suckled piglet, is a useful model for exploring various functions of intestinal cells in vitro $[35,36]$. Because of the significant physiologic and morphologic similarities to enterocytes in vivo, IPEC-J2 cell line has been widely applied to characterize the interactions of enterocytes with RV in vitro [37]. The RV predominantly invades epithelial cells in the proximal intestine thereby causing villous atrophy and crypt hyperplasia. Then it is also accompanied by deadly watery diarrhea, resulting in severe dehydration and death in human and animals [7]. In this study, RV infection decreases viability of IPEC-J2 cells and increases the apoptosis rate, which is consistent with what was previously observed in Caco-2 cells [38]. Moreover, pretreatment IPEC-J2 cells with SB, survival ratio was elevated and apoptosis was rescued. These results indicate SB has an evident protective action against RV-induced IPEC-J2 cell apoptosis. 
The ER is the primary organelle for viral replication and maturation. Accumulated evidences demonstrated that virus infection involves in disrupting homeostasis of the ER and leads to activation of ERS [39-44]. The GRP78 and CHOP are contemporary and novel biomarkers of ERS [45]. In current study, mRNA expressions of GRP78 and CHOP significantly were increased in response to RV infection, indicating RV induces ERS. In normal, PERK, ATF6, and IRE1a are bound by GRP78. When ERS is activated, three transmembrane proteins separate from GRP78 that combines unfolded proteins. Subsequently, PERK and IRE1a are activated by transautophorylation and ATF6 is activated by proteolytic processing [46]. This study found that RV infection significantly increased phosphorylation of PERK but not IRE1a or ATF6. The PERK branch play a vital role in ERS related apoptosis. The activated PERK phosphorylates elF2a on Ser51 site, inhibiting protein translation and synthesis. Subsequently, phosphorylated elF2a selectively initiates the translation of ATF4, which is required in the apoptotic response to ERS [47]. In this study, p-PERK, p-elF2a, cle-caspase9, and cle-caspase3 were significantly increased in RV infection cell, and caused a significant increase of cell apoptosis. Further, inhibition of PERK by GSK effectively reduced the expression of $p$-PERK and p-elF2a, and RV-induced cell apoptosis. These results strongly suggested that PERK-elF2a pathway function as a critical handler in RV-induced cell apoptosis.

The SB is a mineral form of short-chain fatty acid that elicits essential roles in preventing cell apoptosis $[30,48,49]$. The previous study indicated that SB attenuated ERS induced islet $\beta$-cell apoptosis via inhibiting PERK-elF2a signaling pathway in type 2 diabetic rats [31]. To further elucidate the potential mechanism of SB's protective effect on RV-induced cell apoptosis in IPEC-J2, this study examined the abundances of ERS- and apoptosis-related proteins. The present results showed protein expressions of $p$ PERK, p-elF2a, cle-caspase9, and cle-caspase3 were highly increased in response to RV infection. Moreover, pretreatment with SB effectively abolished RV-induced phosphorylation levels of PERK signaling and depressed protein levels of cle-caspase 9 and cle-caspase3. Collectively, these results indicated that reduced PERK-elF2 $a$ signaling is responsible for SB-ameliorated IPEC-J2 apoptosis induced by RV. To our knowledge, this study first note SB protects IPEC-J2 against RV-induced apoptosis through inhibiting PERK-elF2asignaling pathway.

The GPR109a is a G protein-coupled receptor for butyrate and expresses in intestinal epithelium [50], which have been shown that GPR109a recognized as a molecular linking connecting SCFAs with intestinal epithelial cell [51]. It has attracted more attention that butyrate not only plays an important role in anti-inflammatory and immune regulation, but also participates in the protection of intestinal cancer by activating GPR109a [52-55]. This study found SB increased GPR109a mRNA level in IPEC-J2 cells. The siRNA-mediated gene silencing of GPR109a blunts the anti-apoptosis effect of SB and blocks SBmediated suppression of PERK-elF2a signaling pathway, indicting that the protective role of SB might be related to the activation of GPR109a. In agreement with previous reports in piglet and mice. The SB ameliorates the 2, 4, 6-trinitrobenzene sulfonic acid-induced inflammatory response and disruption of epithelial integrity through activating GPR109a [52] and exerted its antidiarrheal effect on weaned piglets by up-regulating the expression of colon tight junction protein in a GPR109a-dependent manner [56]. 
Taken together, these data indicate SB alleviates RV-induced apoptosis through PERK-elF2a signaling pathway in a GPR109a-dependent manner.

In conclusion, this study was the first to provide evidence that RV infection induced cell apoptosis via PERK-elF2a signaling pathway. The SB alleviates RV-induced apoptosis via PERK-elF2a signaling pathway in a GPR109a-dependent manner. These results highlighted a novel mechanism of SB in regulation of RV-induced apoptosis in intestinal epithelial cells.

\section{Abbreviations}

Rotavirus: RV; Endoplasmic reticulum: ER; sodium butyrate: SB; Endoplasmic reticulum stress: ERS; Protein kinase-like ER kinase: PERK; Eukaryotic initiation factor 2 alpha: elF2a; Glucose regulated protein 78: GRP78; C/EBP homologous protein: CHOP; Activating transcription factor 4: ATF4; Multiplicity of infection: MOI; Cell Counting Kit-8: CCK8; Fluorescein isothiocynate: FITC; Propidium iodide: PI

\section{Declarations}

\section{Acknowledgements}

The authors would like to express their sincere thanks to the personnel of these teams for their kind assistance.

\section{Authors' contributions}

Y. Z. and D. C. designed and provided guidance for the experiments. Y. Z., N. H., and Q. J. performed the experiments and wrote the manuscript. L. Z., M. Z., J. J., M. X., M. Y., and J. Y. performed the RT-PCR experiments and assisted in the manuscript preparation. L. S., S. Z., L. N., and L. C. analyzed and interpreted the data. All authors contributed to the experiments.

\section{Funding}

The study was supported by Key Program for the National Natural Science Foundation of China (31730091).

\section{Availability of data and materials}

The datasets produced and/or analyzed during the current study are available from the corresponding author on reasonable request.

\section{Ethics approval and consent to participate}

Not applicable

\section{Consent for publication}


Not applicable.

\section{Competing Interest}

The authors declare that they have no known competing financial interests or personal relationships that could have appeared to influence the work reported in this paper.

\section{Author details}

${ }^{1}$ College of Animal Science and Technology, Sichuan Agricultural University, Chengdu 611130, China.

${ }^{2}$ Institute of Animal Nutrition, Sichuan Agricultural University, Chengdu 611130, China.

${ }^{3}$ Key Laboratory for Animal Disease-Resistance Nutrition of China Ministry of Education, Sichuan Agricultural University, Chengdu, Sichuan 611130, P. R. China.

\section{References}

1. Hyser JM, Estes MK. Rotavirus vaccines and pathogenesis: 2008. Curr Opin Gastroenterol. 2009;25(1):36-43.

2. Woode GN, Bridger JC, Jones JM, Flewett TH, Davies HA, Davis HA, et al. Morphological and antigenic relationships between viruses (rotaviruses) from acute gastroenteritis of children, calves, piglets, mice, and foals. Infect Immun. 1976;14(3):804-10.

3. Mulyani NS, Prasetyo D, Karyana IPG, Sukardi W, Damayanti W, Anggraini D, et al. Diarrhea among hospitalized children under five: a call for inclusion of rotavirus vaccine to the national immunization program in Indonesia. Vaccine. 2018;36(51):7826-31.

4. Wang $\mathrm{H}$, Naghavi M, Allen C, Barber RM, Bhutta ZA, Carter A, et al. Global, regional, and national life expectancy, all-cause mortality, and cause-specific mortality for 249 causes of death, 1980-2015: a systematic analysis for the Global Burden of Disease Study 2015. Lancet. 2016;388:1459-544.

5. Wang P, Goggins WB, Chan EYY. A time-series study of the association of rainfall, relative humidity and ambient temperature with hospitalizations for rotavirus and norovirus infection among children in Hong Kong. Sci Total Environ. 2018;643:414-22.

6. Asma S, Nazish B, Claude YK, Saadia N, Sadia S. Rotavirus: genetics, pathogenesis and vaccine advances. Rev Med Virol. 2018;28(6):e2003.

7. Mao X, Hu H, Xiao X, Chen D, Yu B, He J, et al. Lentinan administration relieves gut barrier dysfunction induced by rotavirus in a weaned piglet model. Food Funct. 2019;10(4):2094-101.

8. Snodgrass DR, Ferguson A, Allan F, Angus KW, Mitchell B. Small intestinal morphology and epithelial cell kinetics in lamb rotavirus infections. Gastroenterology. 1979;76(3):477-81.

9. Shamsollahi HR, Ghoochani M, Sadeghi K, Jaafari J, Masinaei M, Sillanpää M, et al. Evaluation of the physical and chemical characteristics of water on the removal efficiency of rotavirus in drinking water treatment plants and change in induced health risk. Process Saf Environ Prot. 2019;130:6-13. 
10. Prez VE, Gil PI, Temprana CF, Cuadrado PR, Martínez LC, Giordano MO, et al. Quantification of human infection risk caused by rotavirus in surface waters from Córdoba, Argentina. Sci Total Environ. 2015;538:220-9.

11. Naqvi SS, Javed S, Naseem S, Sadiq A, Khan N, Sattar S, et al. G3 and G9 rotavirus genotypes in waste water circulation from two major metropolitan cities of Pakistan. Sci Rep. 2020;10:8665.

12. Prevost B, Lucas FS, Goncalves A, Richard F, Moulin L, Wurtzer S. Large scale survey of enteric viruses in river and waste water underlines the health status of the local population. Environ Int. 2015;79:42-50.

13. Gratacap-Cavallier B, Genoulaz O, Brengel-Pesce K, Soule H, Innocenti-Francillard P, Bost M, et al. Detection of human and animal rotavirus sequences in drinking water. Appl Environ Microbiol. 2000;66(6):2690-2.

14. Mao X, Gu C, Hu H, Tang J, Chen D, Yu B, et al. Dietary lactobacillus rhamnosus GG supplementation improves the mucosal barrier function in the intestine of weaned piglets challenged by porcine rotavirus. PLoS One. 2016;11(1):e0146312.

15. Zhang Q, Xu Y, Chang R, Tong D, Xu X. Transmissible gastroenteritis virus $N$ protein causes endoplasmic reticulum stress, up-regulates interleukin-8 expression and its subcellular localization in the porcine intestinal epithelial cell. Res Vet Sci. 2018;119:109-15.

16. Wu X, Sun L, Zha W, Studer E, Gurley E, Chen L, et al. HIV protease inhibitors induce endoplasmic reticulum stress and disrupt barrier integrity in intestinal epithelial cells. Gastroenterology. 2010;138:197-209.

17. Turpin J, Frumence E, Harrabi W, Haddad JG, El Kalamouni C, Desprès P, et al. Zika virus subversion of chaperone GRP78/BiP expression in A549 cells during URP activation. Biochimie. 2020;175:99105.

18. Malhotra JD, Kaufman RJ. The endoplasmic reticulum and the unfolded protein response. Semin Cell Dev Biol. 2007;18(6):716-31.

19. Gu Y, Wang Y, Bai Y, Liu M, Wang H. Endoplasmic reticulum stress and apoptosis via PERK-elF2aCHOP signaling in the methamphetamine-induced chronic pulmonary injury. Environ Toxicol Pharmacol. 2017;49:194-201.

20. Aw TY. GADD153 sensitized cells to ER stress by down-regulating Bcl2 and perturbing the cellular redox state. Mol Cell Biol. 2001;21(4):1249-59.

21. Puthalakath H, O'Reilly LA, Gunn P, Lee L, Kelly PN, Huntington ND, et al. ER stress triggers apoptosis by activating BH3-only protein Bim. Cell. 2007;129(7):1337-49.

22. Catanzaro N, Meng X. Induction of the unfolded protein response (UPR) suppresses porcine reproductive and respiratory syndrome virus (PRRSV) replication. Virus Res. 2020;276:197820.

23. Shigemi Z, Baba Y, Hara N, Matsuhiro J, Kagawa H, Watanabe T, et al. Effects of ER stress on unfolded protein responses, cell survival, and viral replication in primary effusion lymphoma. Biochem Biophys Res Commun. 2016;469(3):565-72. 
24. Guilloteau P, Martin L, Eeckhaut V, Ducatelle R, Zabielski R, Van Immerseel F. From the gut to the peripheral tissues: the multiple effects of butyrate. Nutr Res Rev. 2010;23(2):366-84.

25. Huang W, Zeng C, Liu J, Yuan L, Liu W, Wang L, et al. Sodium butyrate induces autophagic apoptosis of nasopharyngeal carcinoma cells by inhibiting AKT/mTOR signaling. Biochem Biophys Res Commun. 2019;514(1):64-70.

26. Pant K, Yadav AK, Gupta P, Islam R, Saraya A, Venugopal SK. Butyrate induces ROS-mediated apoptosis by modulating miR-22/SIRT-1 pathway in hepatic cancer cells. Redox Biol. 2017;12:340-9.

27. Gálfi P, Neogrády S, Kutas F, Veresegyházy T. Influence of sodium butyrate on HeLa cell morphology and proliferation. Life Sci. 1985;37(24):2257-68.

28. Chen G, Ran X, Li B, Li Y, Wang W. Sodium butyrate inhibits inflammation and maintains epithelium barrier integrity in a TNBS-induced inflammatory bowel disease mice model. EBioMedicine. 2018;30:317-25.

29. Machado RA, Constantino LDS, Tomasi CD, Rojas HA, Vuolo FS, Vitto MF, et al. Sodium butyrate decreases the activation of NF-KB reducing inflammation and oxidative damage in the kidney of rats subjected to contrast-induced nephropathy. Nephrol Dial Transplant 2012;27(8):3136-40.

30. Liu X, Jiang C, Liu G, Wang P, Shi M, Yang M, et al. Sodium butyrate protects against oxidative stress in human nucleus pulposus cells via elevating PPARy-regulated Klotho expression. Int Immunopharmacol. 2020;85:106657.

31. Hu Y, Liu J, Yuan Y, Chen J, Cheng S, Wang H, et al. Sodium butyrate mitigates type 2 diabetes by inhibiting PERK-CHOP pathway of endoplasmic reticulum stress. Environ Toxicol Pharmacol. 2018;64:112-21.

32. Zhao Y, Ran Z, Jiang Q, Hu N, Yu B, Zhu L, et al. Vitamin D alleviates rotavirus infection through a microrna-155-5p mediated regulation of the TBK1/INF3 signaling pathway in vivo and in vitro. Int $\mathrm{J}$ Mol Sci. 2019;20(14):3562.

33. Pang X, Qiu Y, Gao T, Zurawell R, Neumann NF, Craik S, et al. Prevalence, levels and seasonal variations of human enteric viruses in six major rivers in Alberta, Canada. Water Res. 2019;153:34956.

34. Kadai AM, Bello HS, Ghamba PE, Dauda FA, Abdullahi IN. Environmental survey of rotavirus in sewage water within Maiduguri Metropolis, Nigeria. J Infect Dis. 2020;10(2):207-12.

35. Mariani V, Palermo S, Fiorentini S, Lanubile A, Giuffra E. Gene expression study of two widely used pig intestinal epithelial cell lines: IPEC-J2 and IPI-2I. Vet Immunol Immunopathol. 2009;131(3-4):27884.

36. Koh SY, George S, Brözel V, Moxley R, Francis D, Kaushik RS. Porcine intestinal epithelial cell lines as a new in vitro model for studying adherence and pathogenesis of enterotoxigenic Escherichia coli. Vet Microbiol. 2008;130(1-2):191-7.

37. Liu F, Li G, Wen K, Bui T, Cao D, Zhang Y, et al. Porcine small intestinal epithelial cell line (IPEC-J2) of rotavirus infection as a new model for the study of innate immune responses to rotaviruses and probiotics. Viral Immunol. 2010;23(2):135-49. 
38. Cha Bi C, Cotte-Laffitte J, Sandré C, Esclatine A, Servin AL, Quéro AM, et al. Rotavirus induces apoptosis in fully differentiated human intestinal Caco-2 cells. Virology. 2005;332(2):480-90.

39. Ambrose RL, Mackenzie JM. West Nile virus differentially modulates the unfolded protein response to facilitate replication and immune evasion. J Virol. 2011;85(6):2723-32.

40. Bechill J, Chen Z, Brewer JW, Baker SC. Coronavirus infection modulates the unfolded protein response and mediates sustained translational repression. J Virol. 2008;82(9):4492-501.

41. Cheng G, Feng Z, He B. Herpes simplex virus 1 infection activates the endoplasmic reticulum resident kinase perk and mediates elF-2a dephosphorylation by the $\gamma_{1} 34.5$ protein. J Virol. 2005;79:1379-88.

42. Isler JA, Skalet AH, Alwine JC. Human cytomegalovirus infection activates and regulates the unfolded protein response. J Virol. 2005;79(11):6890-9.

43. Medigeshi GR, Lancaster AM, Hirsch AJ, Briese T, Lipkin WI, Defilippis V, et al. West Nile virus infection activates the unfolded protein response, leading to $\mathrm{CHOP}$ induction and apoptosis. $\mathrm{J}$ Virol. 2007;81(20):10849-60.

44. Pavio N, Romano PR, Graczyk TM, Feinstone SM, Taylor DR. Protein synthesis and endoplasmic reticulum stress can be modulated by the hepatitis $C$ virus envelope protein $E 2$ through the eukaryotic initiation factor 2a kinase PERK. J Virol. 2003;77(6):3578-85.

45. Kim I, Xu W, Reed JC. Cell death and endoplasmic reticulum stress: disease relevance and therapeutic opportunities. Nat Rev Drug Discov. 2008;7(12):1013-30.

46. Zhang K, Kaufman RJ. Signaling the unfolded protein response from the endoplasmic reticulum. J Biol Chem. 2004;279(25);25935-8.

47. Tabas I, Ron D. Integrating the mechanisms of apoptosis induced by endoplasmic reticulum stress. Nat Cell Biol. 2011;13(3):184-90.

48. Sekhavat A, Sun JM, Davie JR. Competitive inhibition of histone deacetylase activity by trichostatin A and butyrate. Biochem Cell Biol. 2007;85(6):751-8.

49. Zhang L, Du J, Yano N, Wang H, Zhao YT, Dubielecka PM, et al. Sodium butyrate protects against high fat diet-induced cardiac dysfunction and metabolic disorders in type II diabetic mice. Cell Biochem. 2017;118(8): 2395-408.

50. Ganapathy V, Thangaraju M, Prasad PD, Martin PM, Singh N. Transporters and receptors for shortchain fatty acids as the molecular link between colonic bacteria and the host. Curr Opin Pharmacol. 2013;13(6):869-74.

51. Blad CC, Tang C, Offermanns S. G protein-coupled receptors for energy metabolites as new therapeutic targets. Nat Rev Drug Discov. 2012;11(8):603-19.

52. Chen G, Ran X, Li B, Li Y, He D, Huang B, et al. Sodium butyrate inhibits inflammation and maintains epithelium barrier integrity in a TNBS-induced inflammatory bowel disease mice model. EBioMedicine. 2018;30:317-25.

53. Elangovan S, Pathania R, Ramachandran S, Ananth S, Padia RN, Lan L, et al. The niacin/butyrate receptor GPR109A suppresses mammary tumorigenesis by inhibiting cell survival. Cancer Res. 
2014;74(4):1166-78.

54. Guo W, Liu J, Sun J, Gong Q, Ma H, Kan X, et al. Butyrate alleviates oxidative stress by regulating NRF2 nuclear accumulation and H3K9/14 acetylation via GPR109A in bovine mammary epithelial cells and mammary glands. Free Radic Biol Med. 2020;152:728-42.

55. Singh N, Gurav A, Sivaprakasam S, Brady E, Padia R, Shi H, et al. Activation of Gpr109a, receptor for niacin and the commensal metabolite butyrate, suppresses colonic inflammation and carcinogenesis. Immunity. 2014;40(1):128-39.

56. Feng W, Wu Y, Chen G, Fu S, Li B, Huang B, et al. Sodium butyrate attenuates diarrhea in weaned piglets and promotes tight junction protein pxpression in colon in a GPR109A-dependent manner. Cell Physiol Biochem. 2018;47(4):1617-29.

\section{Tables}

\section{Table 1}

Primer sequences and optimal annealing temperatures (OAT) of genes selected for real-time PCR 


\begin{tabular}{|c|c|c|c|}
\hline Name & Sequence $\left(5^{\prime}-3^{\prime}\right)$ & OAT $\left({ }^{\circ} \mathrm{C}\right)$ & GenBank ID \\
\hline RV-QF & TCAGTTCGTCAGGAATATGC & 53.5 & AF317123 \\
\hline RV-QR & CTTGAAGGTGAGTAGTTGGT & & \\
\hline GPR109a-QF & ATGCTGGACCCTTTGGTGTAT & 56.4 & XM021072989 \\
\hline GPR109a-QR & GGCTTGTGCTGCGGTTATT & & \\
\hline GRP78-QF & TCGGCGATGCAGCCAAGAAC & 59.8 & XM001927795 \\
\hline GRP78-QR & CGGGTCATTCCATGTCCGGC & & \\
\hline PERK-QF & CTGCCACTTCAGCATCATTC & 61.7 & XM021086085 \\
\hline PERK-QR & TTCCATCCAGGTCACCACAT & & \\
\hline IRE1-QF & CGTCCTGGATCCAAAACT & 54 & XM005668695 \\
\hline IRE1-QR & GTCAGATAGCGCAGGGTCTC & & \\
\hline ATF6-QF & CCGAAGAGAAGAGCCATCTG & 60.3 & XM021089515 \\
\hline ATF6-QR & TCCTTTGATTTGCAGGGTTC & & \\
\hline CHOP-QF & САСТСТTGAСССТGССТСТС & 58.4 & NM001144845 \\
\hline CHOP-QR & GACTGGAATCAGGCGAGTGT & & \\
\hline $\mathrm{Bcl}-2-\mathrm{QF}$ & TGTGTGTGGAGAGCGTCAACC & 62.5 & XM021099593 \\
\hline $\mathrm{Bcl}-2-\mathrm{QR}$ & CAGAGACAGCCAGGAGAAATCAA & & \\
\hline Bax-QF & CCACCAGCTCTGAGCAGATCA & 61.3 & XM003127290 \\
\hline Bax-QR & GCCGCCACTCGGAAAAA & & \\
\hline Caspase9-QF & GTCTGCCCACACCTAGTGAC & 61.7 & XM003127618 \\
\hline Caspase9-QR & AGGGGTCCCAGCCTCATTAT & & \\
\hline Caspase3-QF & TGGCGTGTCAGAAAATACCAGT & 60.5 & NM214131 \\
\hline Caspase3-QR & GATCCGTCCTTTGAATTTCGCC & & \\
\hline$\beta$-actin-QR & TCTGGCACCACACCTTCT & 59.0 & U07786 \\
\hline$\beta$-actin-QF & TGATCTGGGTCATCTTCTCAC & & \\
\hline
\end{tabular}

\section{Figures}


(A)

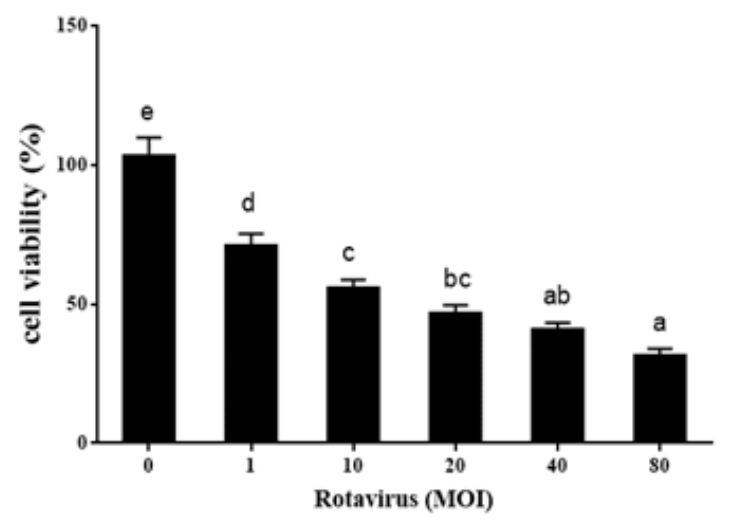

(C)

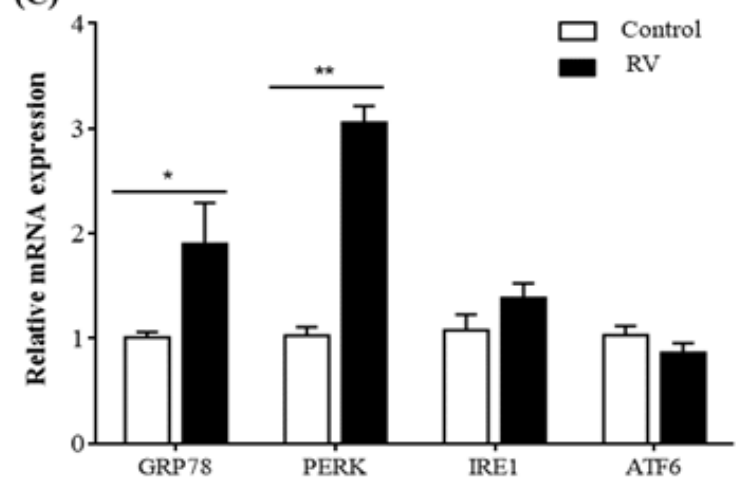

(B)
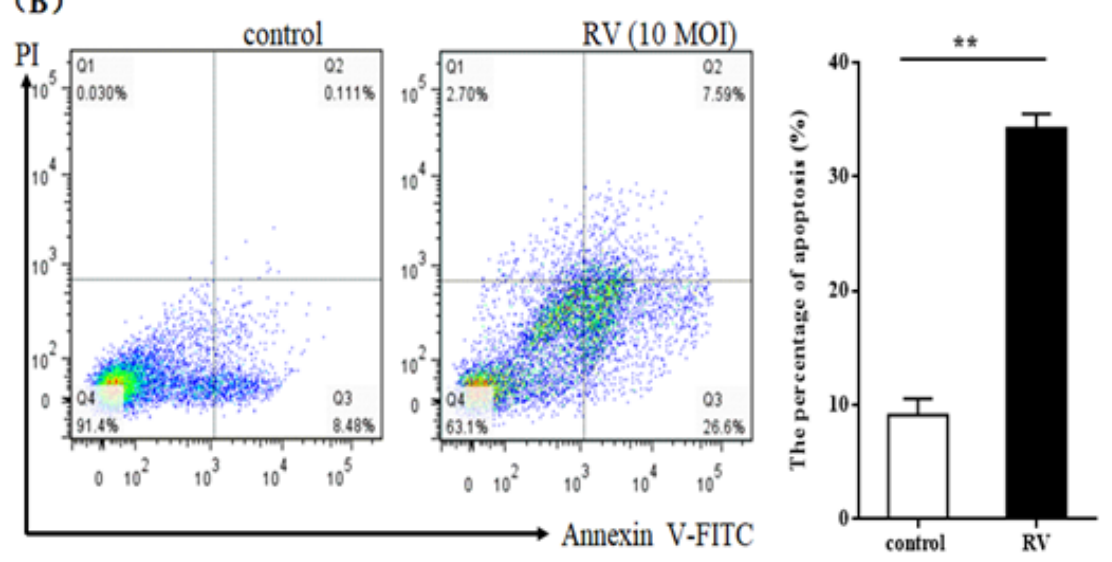

(D)

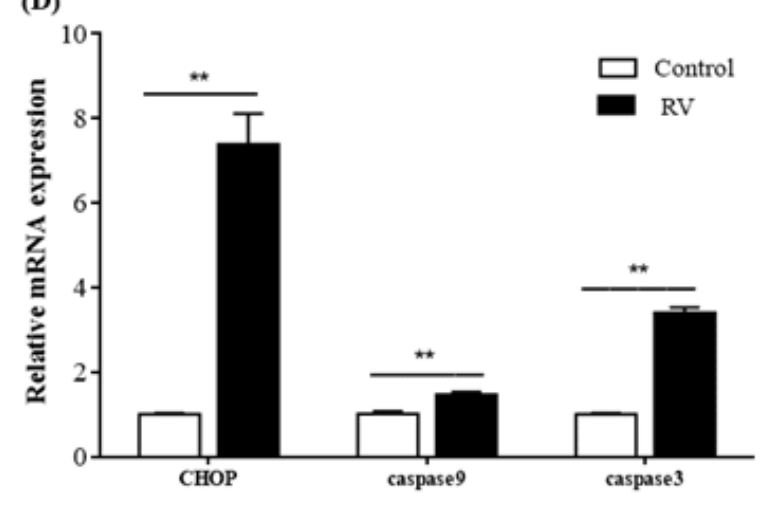

Figure 1

The effect of RV infection on cell viability and apoptosis in IPEC-J2 cells. A, cell viability was measured by CCK8 assay after RV infection for $24 \mathrm{~h}$. B, apoptotic populations of cells double stained with $\mathrm{Pl}$ - and FITC-labeled Annexin V were measured by flow cytometry. $C$ and $D$, the effect of RV infection on the mRNA expression of the ER stress-mediated apoptosis related genes in IPEC-J2 cells. ${ }^{*} P<0.05,{ }^{*} P<0.01$, data are expressed as means \pm S.D. from three independent experiments at least. 

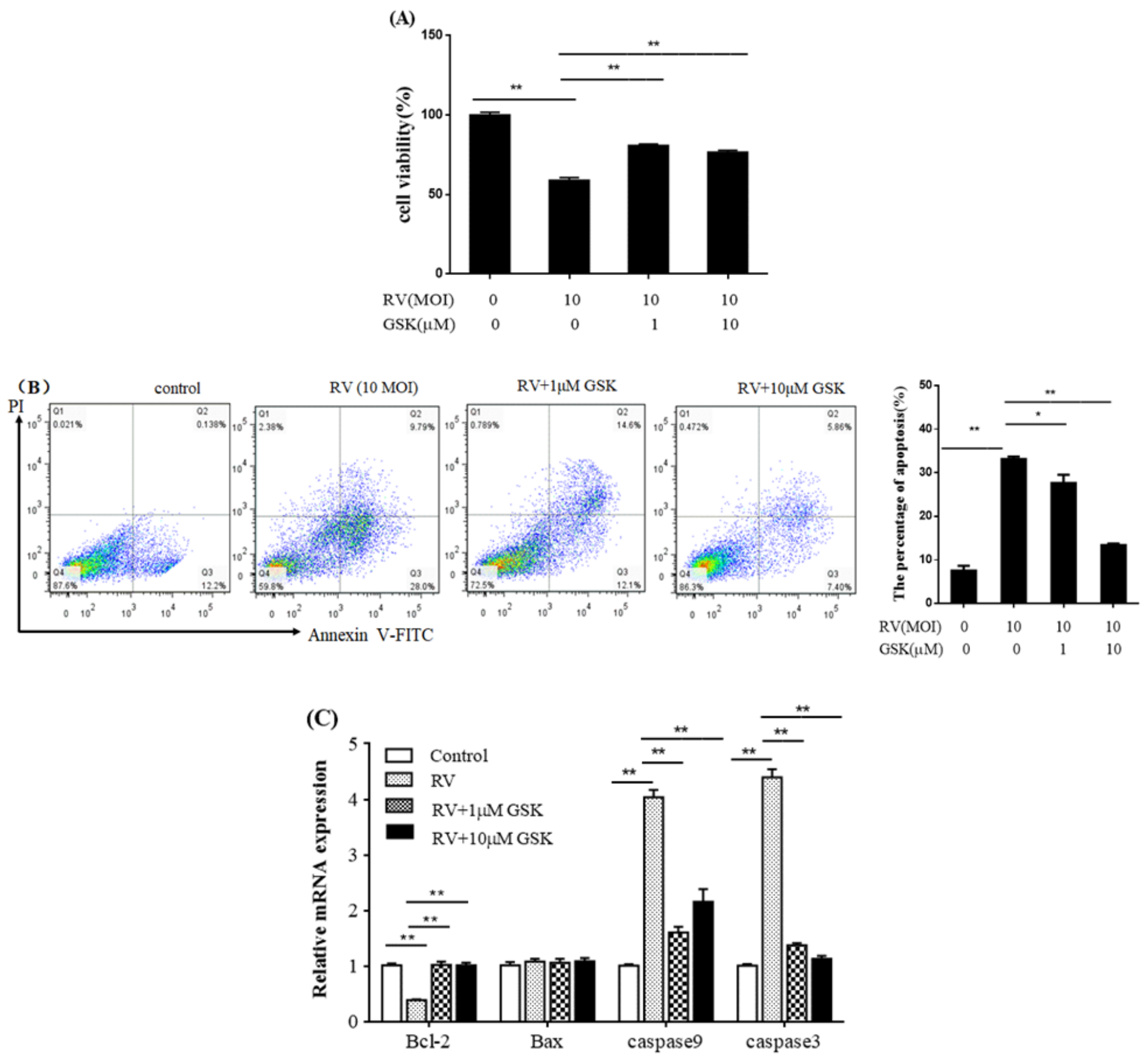

Figure 2

The effect of PERK inhibitor (GSK) on cell viability and apoptosis in IPEC-J2 cells. Cells were pre-treated with an apoptosis inhibitor (GSK, 1 or $10 \mu \mathrm{M}$ ) for $24 \mathrm{~h}$, followed by challenge with RV (10 MOI) for $1 \mathrm{~h}$, and then incubated with DMEM/F12 for a further $24 \mathrm{~h}$. A, cell viability was measured by CCK8 assay after $\mathrm{RV}$ infection for $24 \mathrm{~h}$. B, apoptotic populations of cells double stained with PI- and FITC-labeled Annexin V were measured by flow cytometry. $\mathrm{C}$, the effect of RV infection on the mRNA expression of apoptosis related genes in IPEC-J2 cells. ${ }^{*} P<0.05,{ }^{*} \mathrm{P}<0.01$, data are expressed as means \pm S.D. from three independent experiments at least. 
(A)

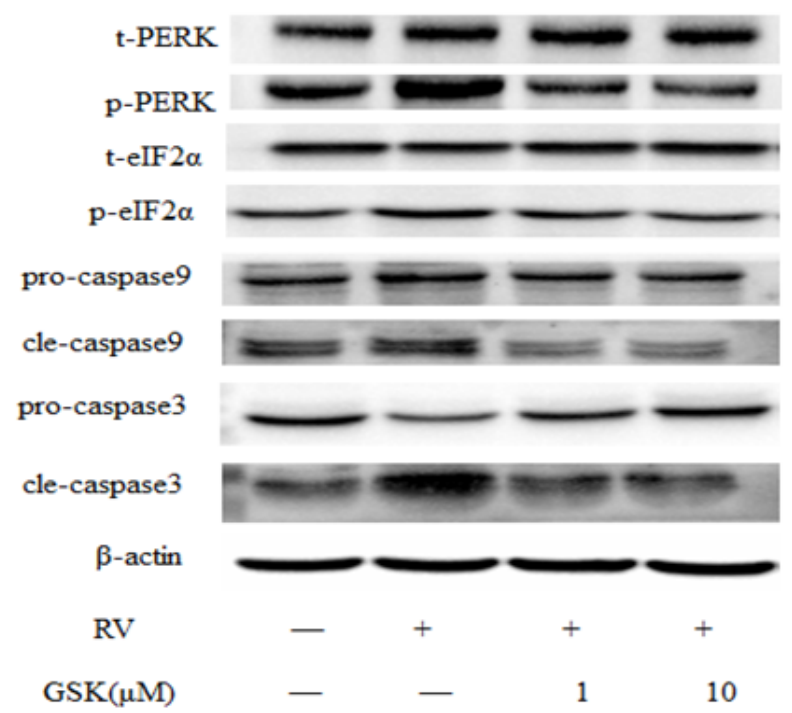

(B)
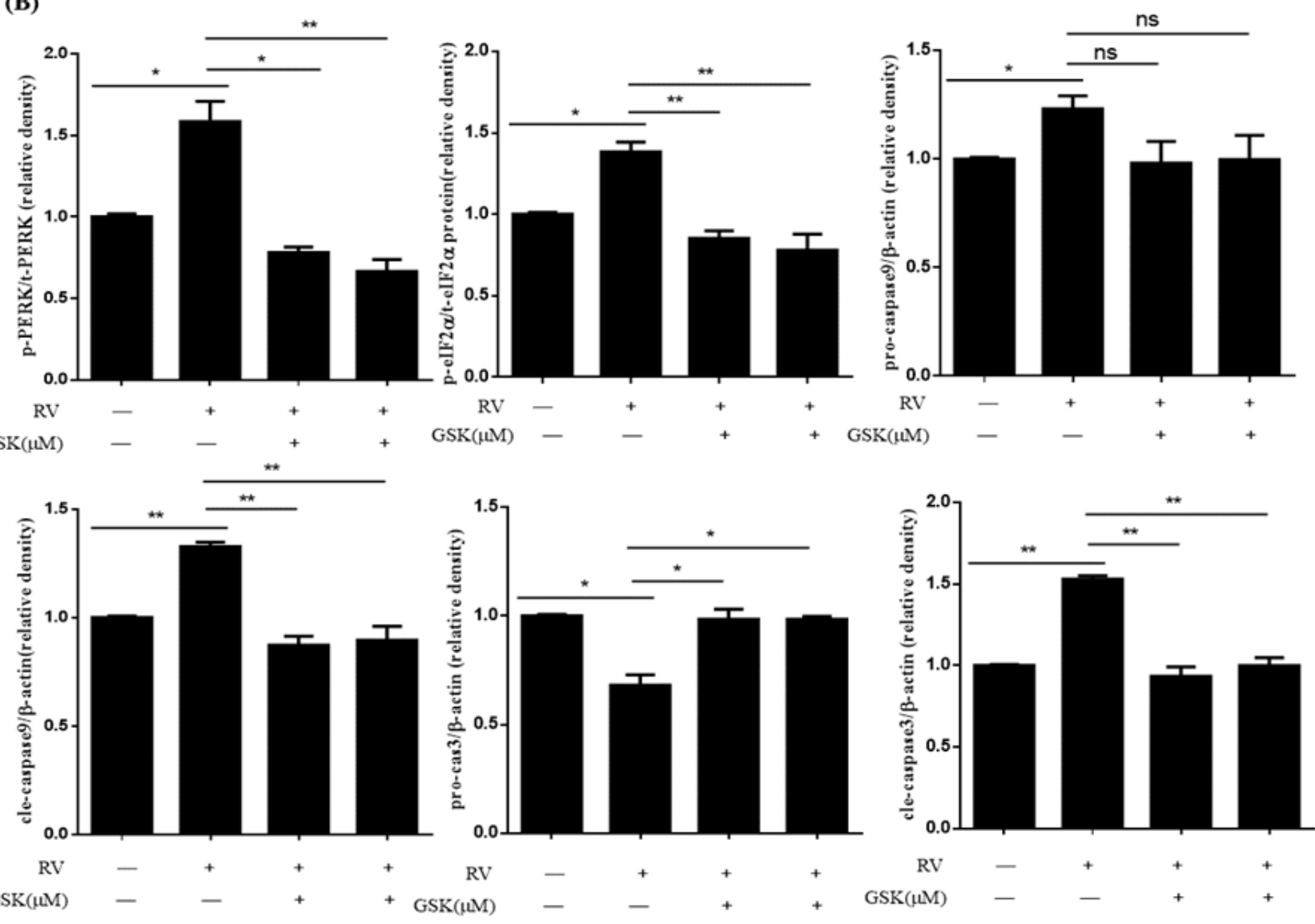

Figure 3

The PERK inhibitor (GSK) alleviated RV induced apoptosis via PERK-elF2a signaling pathway in IPEC-J2 cells. Cells were pre-treated with the PERK inhibitor (GSK, 1 or $10 \mu \mathrm{M})$ for $24 \mathrm{~h}$, followed by challenge with RV $(10 \mathrm{MOI})$ for $1 \mathrm{~h}$, and then incubated with DMEM/F12 for a further $24 \mathrm{~h}$. A, the t-PERK, p-PERK, t-elF2a, p-elF2a, pro-caspase9, cle-caspase9, pro-caspase3, and cle-caspase3 protein levels were determined by western blot. B, results were expressed as the ratio of p-PERK and t-PERK, p-elF2 $a$ and t-elF2a, pro- 
caspase 9 and $\beta$-actin, cle-caspase 9 and $\beta$-actin, pro-caspase 3 and $\beta$-actin, and cle-caspase 3 and $\beta$-actin protein levels. Equal loading was monitored with anti- $\beta$-actin antibody. ${ }^{*} P<0.05, * \star P<0.01$, data are expressed as means \pm S.D. from three independent experiments at least.
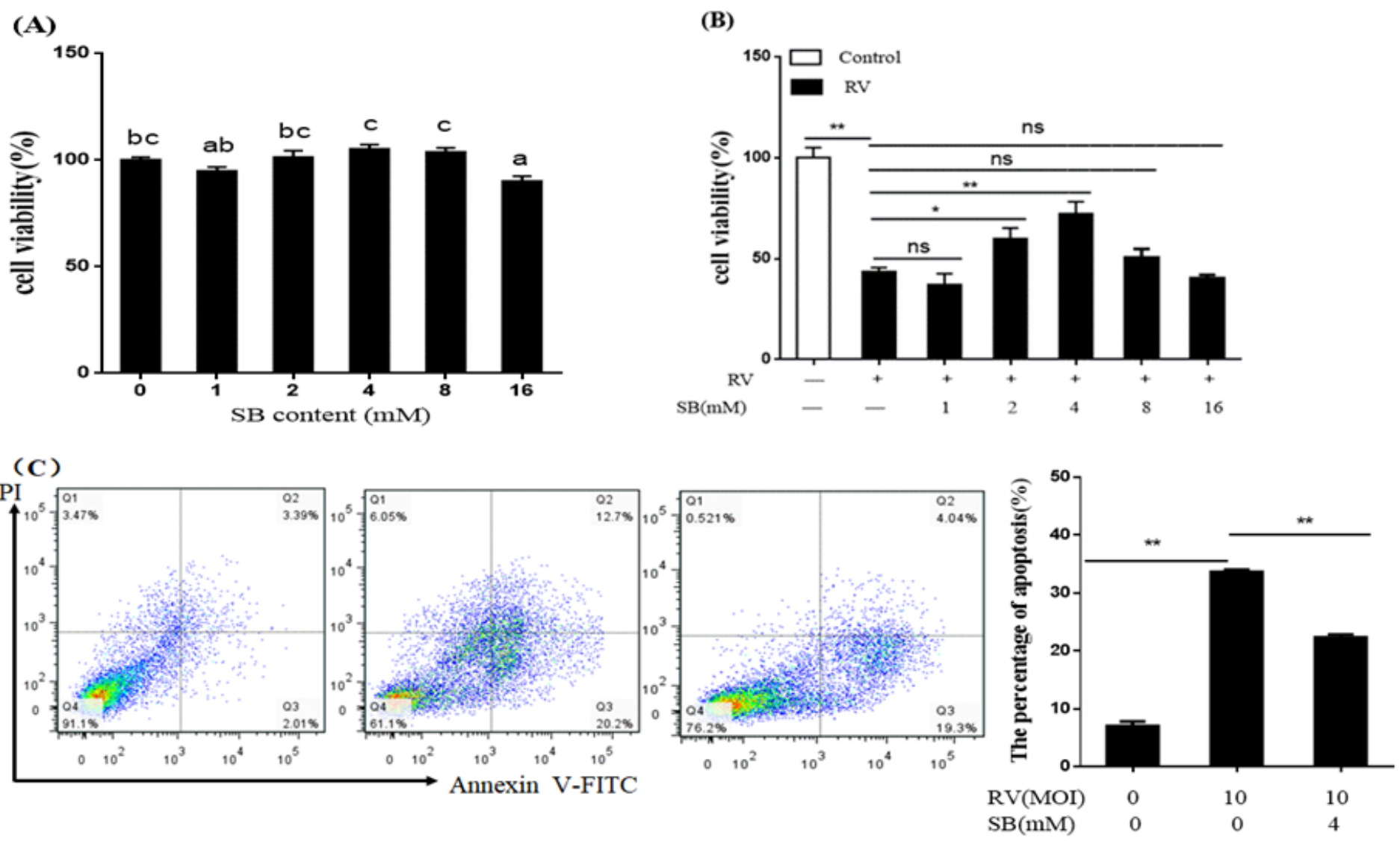

Figure 4

The effects of SB on RV-induced proliferation inhibition and apoptosis of IPEC-J2 cells. A, The change of cell viability after treatment with $\mathrm{SB}(0,1,2,4,8,16 \mathrm{mmol} / \mathrm{L})$ for $24 \mathrm{~h}$. B, The IPEC-J2 cells were pretreated with SB $(0,1,2,4,8,16 \mathrm{mmol} / \mathrm{L})$ for $24 \mathrm{~h}$, followed by challenge with or without RV (10 MOl) for $1 \mathrm{~h}$, and then incubated with DMEM/F12 for a further $24 \mathrm{~h}$. Cell viability was detected by CCK-8 assay. C, apoptotic populations of cells double stained with PI- and FITC-labeled Annexin V were measured by flow cytometry. ${ }^{*} \mathrm{P}<0.05,{ }^{*} \mathrm{P}<0.01$, data are expressed as means \pm S.D. from three independent experiments at least. 


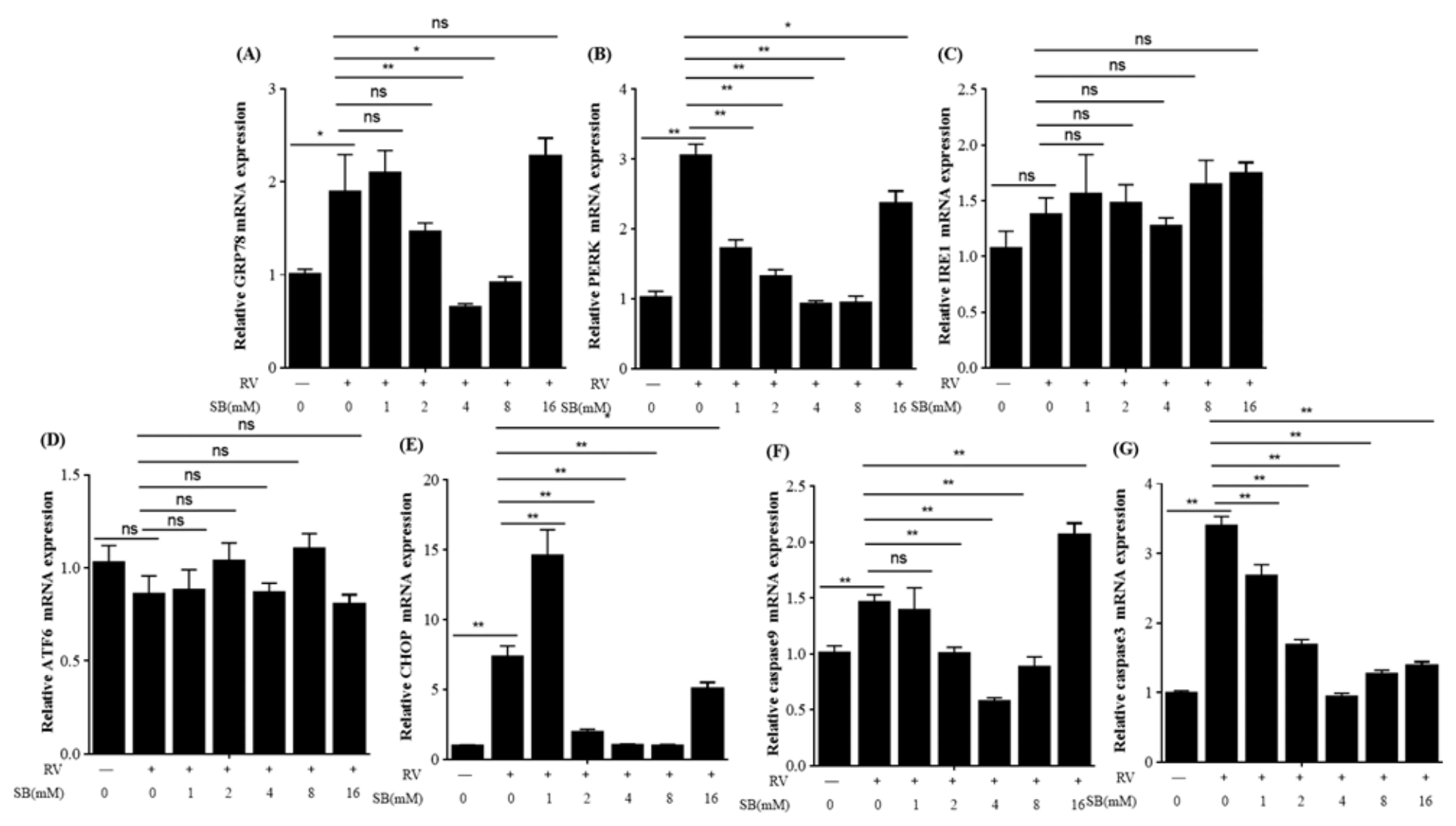

Figure 5

Effect of SB on RV induced ER stress-mediated apoptosis related gene relative expressions in IPEC-J2 cells. The IPEC-J2 cells were pretreated with SB $(0,1,2,4,8,16 \mathrm{mmol} / \mathrm{L})$ for $24 \mathrm{~h}$, followed by challenge with or without RV (10 MOI) for $1 \mathrm{~h}$, and then incubated with DMEM/F12 for a further 24 h. A, B, C, D, E, F, and G, GRP78, PERK, IRE1, ATF6, CHOP, caspase9, and caspase3 mRNA expression were measured by qRT-PCR. ${ }^{*} P<0.05,{ }^{*} P<0.01$, data are expressed as means \pm S.D. from three independent experiments at least. 


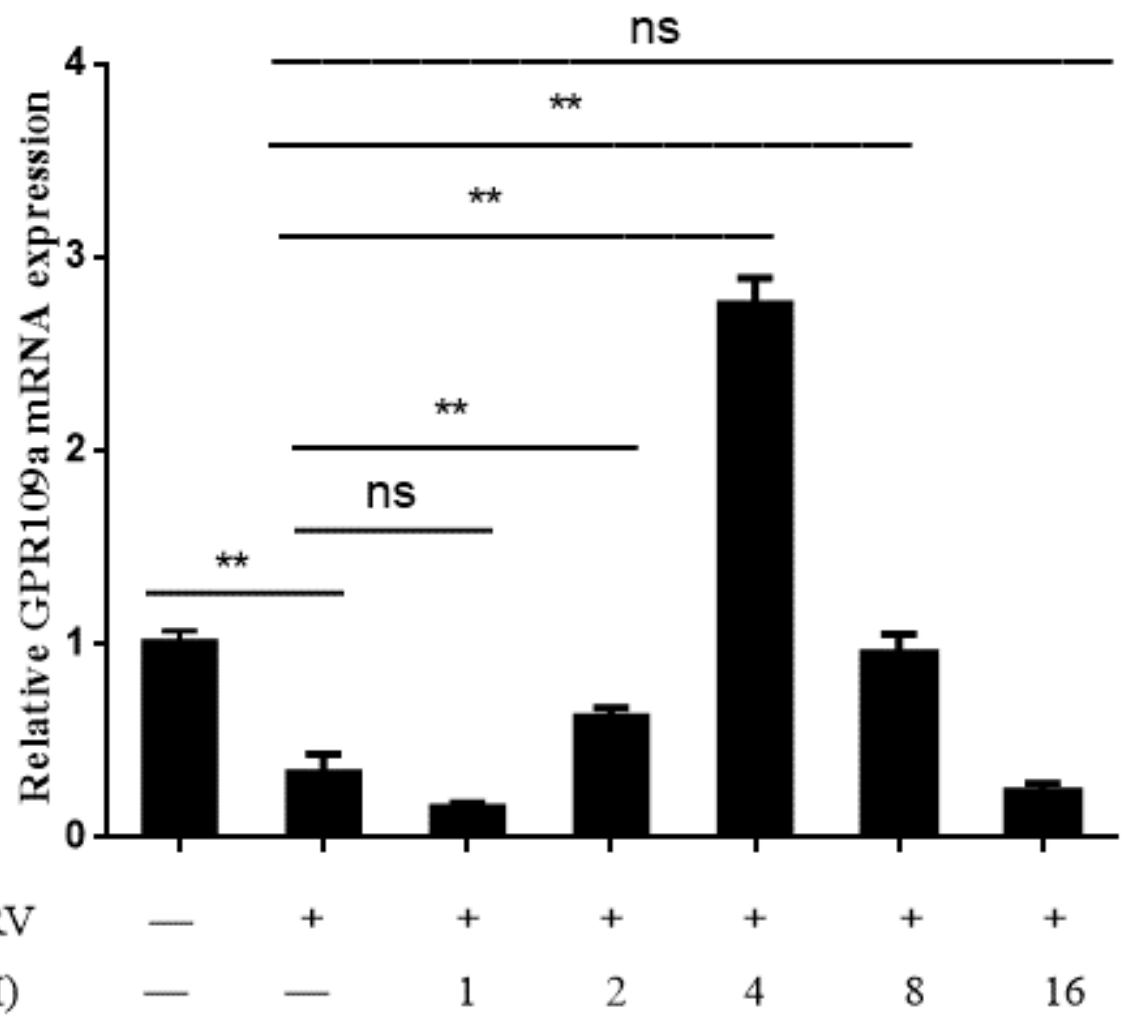

Figure 6

Effect of SB on GPR109a mRNA expression in RV-infected IPEC-J2 cells. The IPEC-J2 cells were pretreated with $\mathrm{SB}(0,1,2,4,8,16 \mathrm{mmol} / \mathrm{L})$ for $24 \mathrm{~h}$, followed by challenge with or without RV (10 MOI) for $1 \mathrm{~h}$, and then incubated with SB $(0,1,2,4,8,16 \mathrm{mmol} / \mathrm{L})$ for a further $24 \mathrm{~h}$. GPR109a mRNA expression was measured by qRT-PCR. ${ }^{\star} P<0.05$, ${ }^{\star \star} \mathrm{P}<0.01$, data are expressed as means \pm S.D. from three independent experiments at least. 

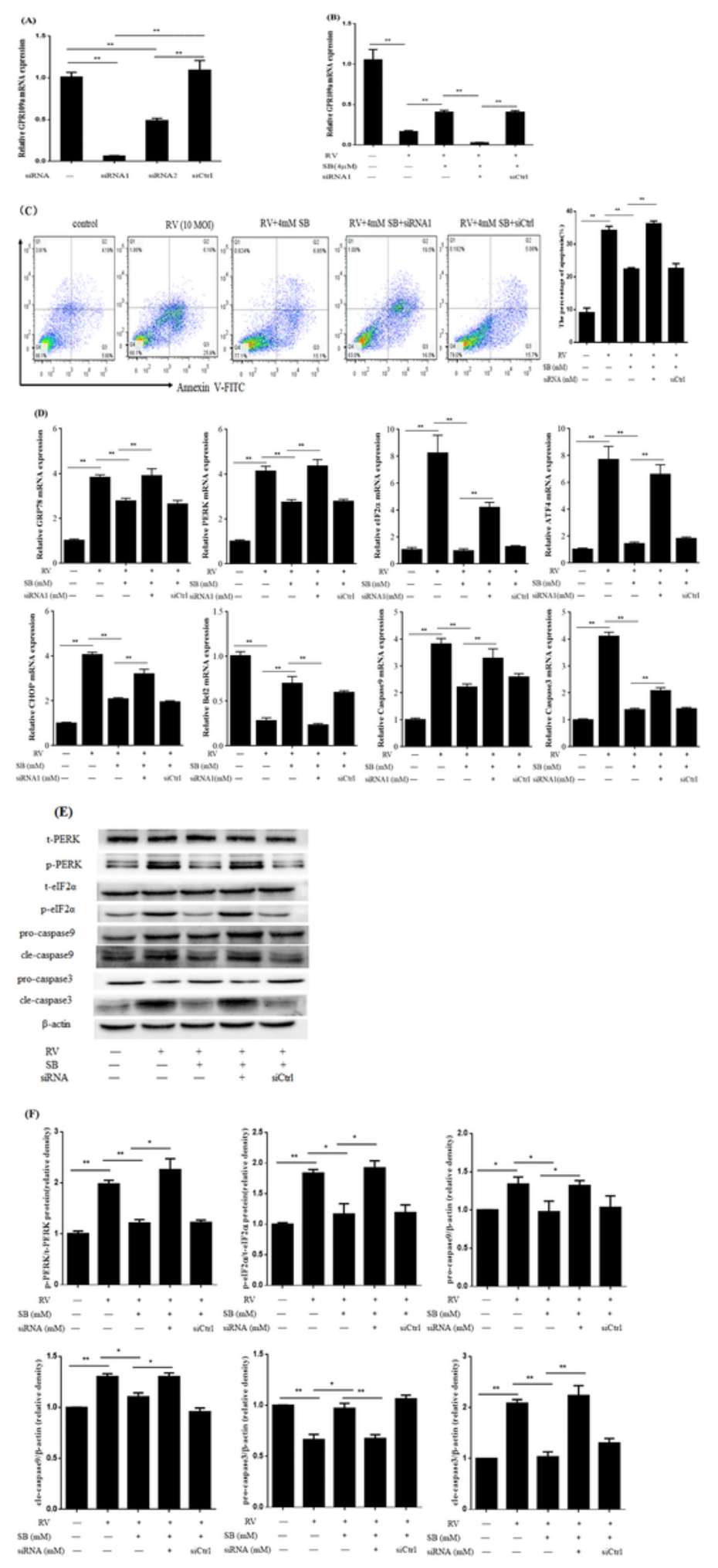

Figure 7

GPR109a is necessary for SB's protection functions in RV infected IPEC-J2. A, IPEC-J2 were transfected with constructed GPR109a small interfering RNAs (GPR109a siRNA1 and siRNA2) or its negative control (siCtrl). Then, cells were pretreated with SB $(4 \mathrm{mmol} / \mathrm{L})$ for $24 \mathrm{~h}$, followed by challenge with or without RV $(10 \mathrm{MOI})$ for $1 \mathrm{~h}$, and then incubated with SB $(4 \mathrm{mmol} / \mathrm{L})$ for a further $24 \mathrm{~h}$. A and B, qRT-PCR was used to assess the mRNA expression of GPR109a. C, apoptotic populations of cells double stained with PI- and 
FITC-labeled Annexin V were measured by flow cytometry. D, GRP78, PERK, elF2a, ATF4, CHOP, Bcl2, caspase9, and caspase 3 mRNA expression was measured by qRT-PCR transfected with siCtrl or siRNA targeting GPR109a. E, Protein expressions of t-PERK, p-PERK, t-elF2a, p-elF2a, pro-caspase9, clecaspase9, pro-caspase3, and cle-caspase3 were determined by western blotting in IPEC-J2 cells transfected with siCtrl or siRNA targeting GPR109a. F, results were expressed as the ratio of $p$-PERK and $t-$ PERK, p-elF2 $\alpha$ and t-eIF2a, pro-caspase 9 and $\beta$-actin, cle-caspase 9 and $\beta$-actin, pro-caspase 3 and $\beta$-actin, and cle-caspase 3 and $\beta$-actin protein levels. Equal loading was monitored with anti- $\beta$-actin antibody. ${ }^{*} P<0.05,{ }^{* *} P<0.01$, data are expressed as means \pm S.D. from three independent experiments at least. 